\title{
Herbert Daniel e a luta contra o estigma da AIDS
}

\author{
Herbert Daniel and the Fight Against the Stigma Associated with AIDS
}

\begin{abstract}
João Nemi Neto
Doutor em Hispanic and Luso-Brazilian Literatures and Languages pela City University of New York Professor do Departamento de Latin American and Iberian Cultures da Columbia University in2395@columbia.edu
\end{abstract}

\begin{abstract}
Resumo: Este artigo pretende discutir e analisar a obra ensaística e ficcional de Herbert Daniel desde seu retorno do exílio em início dos anos 80 até a sua morte em decorrência da AIDS em 1992. Através da análise de seus textos, pretende-se mostrar que Herbert Daniel levanta questões importantes para a disseminação do preconceito contra as pessoas com HIV e também discute o pânico moral instaurado com a epidemia e a morte civil dos pacientes e pessoas com HIV. Os textos de Daniel propõem um diálogo amplo e irrestrito em relação ao preconceito decorrente da epidemia da AIDS traçando assim um detalhado painel que contribui para uma compreensão mais ampla da história da AIDS no Brasil.
\end{abstract}

Palavras-chaves: HIV/AIDS, Herbert Daniel, morte civil.

\begin{abstract}
This paper aims at discussing and analyzing both fictional and essayistic works by Herbert Daniel from his return to Brazil after the exile in the beginning of the 1980s until his death due to complications related to AIDS in 1992. Through the analysis of his books, this paper will show that Daniel raises important questions in order to disseminate the prejudice against PLWH - People Living with HIV/AIDS. Daniel also discusses the moral panics the epidemics brought into light and the civil death of PLWH. Daniel's texts propose a broad and unrestricted dialogue in regards to the prejudice due to the AIDS epidemics creating a detailed description that contributes to a better understanding of the history of AIDS in Brazil.
\end{abstract}

Keywords: HIV/AIDS, Herbert Daniel, civil death. 


\section{Introdução}

Na literatura recente, vários livros têm-se destacado ao lidar de maneira direta sobre questões relacionadas à AIDS e HIV. Depois daquela viagem, de Valéria Piassa Polizzi e Uma vida positiva, de Rafael Bolacha são dois exemplos que merecem destaque por trazerem à tona questões importantes para o debate e conscientização. $\mathrm{O}$ primeiro escrito ainda no final dos anos 90 ajudou, entre outros sucessos, a diminuir o estigma associado ao vírus e levar a discussão de maneira aberta às escolas e jovens do Brasil e de outros países. O segundo, publicado em 2013, além de manter a importante discussão sobre o estigma e preconceito, apresenta aos leitores questões relacionadas às pessoas que vivem com o vírus após os avanços da medicina que a autora do primeiro livro presenciou logo no início.

Tais textos são importantes para o constante diálogo que ainda se faz necessário a respeito da AIDS e HIV nos dias de hoje. Já são mais de trinta anos desde a detecção do vírus e início de tratamentos e campanhas preventivas. Contudo, muitas pessoas ainda são infectadas diariamente e o estigma associado à doença também é uma questão importante para as pessoas que vivem com o vírus.

Muito tem-se escrito sobre a AIDS no Brasil e a evolução do ativismo político, da ciência e das maneiras como o preconceito tem marcado a vida das pessoas afetadas - direta e indiretamente - pela epidemia (GALVÃO, 2000; NUNN, 2009; MARQUES, 2003; BASTOS, 1999 entre outros). Este artigo pretende contribuir com a discussão trazendo à luz um dos primeiros ativistas brasileiros e vozes contra a discriminação contra as pessoas soropositivas: Herbert Daniel. Ao voltar para o Brasil após sua demorada anistia política, Daniel empenhou-se na luta pelos direitos humanos e já nos anos 80 tornou-se uma das principais vozes na luta contra a AIDS e os estigmas associados à doença. Ele esteve associado à ABIA - Associação Brasileira Interdisciplinar de Aids - desde a sua criação e até a sua morte em 1992 produziu ensaios, romances e outros textos procurando discutir temas relacionados à AIDS e ao HIV. Daniel acabou se tornando referência no combate ao vírus e ao estigma associado à doença estabelecendo canais de comunicação entre o Brasil e o mundo.

Mesmo não terminando os estudos médicos (Herbert Daniel abandonou a faculdade de medicina no quarto ano), seu trabalho no combate à AIDS/ HIV e ao estigma se associou aos trabalhos na área de medicina e antropologia provando de extrema importância para a história da doença e dos agentes relacionados a ela. Neste 
artigo, pretende-se discutir alguns de seus textos e de que maneiras Herbert Daniel, exestudante de medicina, aproveitou-se do discurso médico-legal para tentar debater questões relevantes, não só para as pessoas vivendo com o vírus, mas também para toda a sociedade. Através de seus textos teóricos, ensaios, manifestos e romances, Herbert Daniel deixou uma obra de extrema importância para entendermos as primeiras reações à epidemia no Brasil nos anos 80 e traçarmos juntamente com os estudos médicos, antropológicos e legais uma possível historiografia da epidemia no Brasil através de seus principais agentes.

\section{Herbert Daniel}

Herbert Eustáquio de Carvalho ou Herbert Daniel, nome escolhido após o exílio durante a ditadura, foi um importante membro da guerrilha contra o regime ditatorial brasileiro durante as décadas de 60 e 70 até o seu exílio, primeiro em Portugal e depois para a França. Mencionado por quase todos os participantes dos movimentos de guerrilha no Brasil como importante figura durante a ditadura, ele participou entre outras ações do sequestro do embaixador alemão ao lado de Alfredo Sirkis. Após seu retorno ao Brasil envolveu-se com questões relacionadas aos direitos humanos, ecologia, movimento homossexual e AIDS/ HIV chegando a ser um anticandidato à presidência nas eleições de 1989. No vídeo de lançamento da sua campanha, Herbert Daniel diz que resolveu ser candidato porque,

no momento em que descobri que estava doente da AIDS, descobri que fundamental é garantir a sua própria vida e dizer eu estou vivo apesar do preconceito que condena o doente de AIDS à morte civil. Este é o pior tipo de preconceito, quando você não tem mais direito nenhum porque você já está morto. Isso é uma coisa que o doente de AIDS tem em comum com todos os brasileiros. (FUNDAÇÃO, 1989.: s.p).

Mineiro de nascença, "Estudante de medicina na UFMG; 1,64m, crítico de cinema no rádio, Belô...” (DANIEL, 1982: s.p.), Daniel chegou a ser chamado de "o último exilado" por Henfil e Alfredo Sirkis já que mesmo após o retorno de todos os políticos exilados, ele encontrou resistência dentro até dos grupos de anistia. Sirkis 
(1998) no posfácio de seu livro "Os carbonários: memórias da guerrilha perdida” diz que,

Daniel, no entanto, só pôde regressar dois anos depois. Permaneceu em Paris e ficou sendo conhecido como o "ultimo exilado", o que inspirou até um personagem do Jô Soares, o Sebá. Enquanto esperava a solução do seu caso, Daniel lia e escrevia muito e trabalhava numa sauna gay. Finalmente de regresso, em 81, Daniel lançou alguns livros que preparara em Paris e escreveu vários outros, alguns autênticas preciosidades, mas que nunca chegaram a um grande público (SIRKIS, 1998: s.p.).

Sobre o seu regresso, em 1979 Herbert Daniel escreveu uma carta explicando que ainda não havia recebido anistia. Lampião da Esquina (março, 1980), um jornal de ativismo homossexual foi o único meio que publicou sua carta que dizia, entre outras coisas, "sou um dos poucos exilados que restam fora das margens que o governo quer impor entre anistiáveis e condenáveis" (DANIEL, 1980: 10).

As razões não eram claras, mas de acordo com o autor, o consulado brasileiro na França disse que ele deveria terminar sua sentença até 1981, contudo como explicar a "anistia ampla, geral e irrestrita" propaganda pelo governo em 1979? Em seu livro Passagem para o próximo sonho, Daniel explica que sua homossexualidade talvez tenha sido um dos motivos de seu "não-retorno". Daniel menciona uma reunião do Comitê Brasil pela Anistia no qual a carta (que seria publicada no "Lampião da Esquina") não foi lida porque ele era "simplesmente uma bicha".

Vários autores que escreveram sobre a ditadura mencionam a "questão" sexual de Daniel. Na biografia da presidenta Dilma Rousseff, por exemplo, Amaral diz que, "na barra-pesada de 1969, Dilma era uma das poucas que entreviam a segunda angústia de Herbert, nos papos que ela costumava regar com batida de limão, preparada na cozinha do aparelho". (AMARAL, 2011: 55)

Daniel escreveu sobre o exílio e a homossexualidade em Passagem para o próximo sonho (livro que teve o título sugerido de "O último exilado", mas Herbert Daniel resistiu às pressões do mercado e manteve seu título mais metafórico). Após seu retorno ao Brasil, Herbert Daniel tornou-se um ativista pelos direitos da população LGBT, direitos humanos e ecologia ao mesmo tempo em que ele passou a escrever sobre HIV/AIDS tanto no âmbito ensaístico quanto na literatura. 
Nos primeiros anos de sua volta ao Brasil, Herbert se filia ao Partido dos Trabalhadores, o PT. Após divergências, em 1986, juntamente com outros dissidentes do PT, participa da fundação do Partido Verde no Brasil. Pelo PV, Herbert Daniel lança uma anticandidatura à presidência da república para as eleições de 1989, ano em que é diagnosticado com tuberculose ganglionar e descobre ser portador do vírus HIV. Apesar de convalescido, a campanha, no entanto, é mantida. Essa foi a primeira e a única vez que um candidato assumidamente homossexual e soropositivo se candidatou a tal cargo político no país. Como explica João Silvério Trevisan:

Há também o gesto significativo de Herbert Daniel: após deixar clara sua situação de homossexual infectado pelo vírus da Aids, integrou-se na chapa de Fernando Gabeira, como candidato à vice-presidência da República, em 1989, pelo Partido Verde. Seu gesto foi sem dúvida simbólico daquilo que vinha ocorrendo no decorrer da década: homossexuais tomavam seus lugares para além do gueto e, na condição de cidadão/ãs, reivindicavam sua parcela de culpa no pecado de ser brasileiro. (TREVISAN, 2004: 319)

Já em 1989, Daniel passa a fazer parte, juntamente com Betinho e outros intelectuais e ativistas, da ABIA - Associação Brasileira Interdisciplinar de Aids. A ABIA desde o início, de acordo com Bastos (1999: 84) mantinha um estilo acadêmico que uniu antropólogas como Jane Galvão e Carmen Dora Guimarães e ativistas como Herbert Daniel. Em um dos boletins da ABIA, de 1989, Daniel juntamente com Guimarães e Galvão publicam “A questão dos preconceitos” (ABIA 1989a: 5). Tal texto debate os estigmas e preconceitos associados à doença que vão além da questão de saúde pública.

\section{AIDS e o estigma social}

Desde os primeiros casos detectados, o HIV e AIDS foram ligados a práticas sexuais entre homens. Chegou a ser conhecido como "câncer gay" e GRID - Gay Related Imuno Deficiency. As primeiras notícias tanto nos Estados Unidos e Europa quanto no Brasil relatam uma 'misteriosa doença' entre homossexuais. A Revista Veja de 28 de novembro de 1984, por exemplo, publicava estatísticas sobre a doença dizendo que $70 \%$ dos infectados eram homossexuais. Ainda que as estatísticas já desde os anos 
90 comprovem que não se pode falar em 'grupos de risco', tal estigma acabou marcando os homens que praticam sexo entre homens e, de certa maneira, formando a identidade homossexual - gay - nos anos 80 e posteriormente. Em 1993, por exemplo, o conselho nacional de pesquisa norte-americano (National Research Council) publicou um estudo afirmando que a AIDS teria um impacto muito pequeno na vida da maioria dos americanos (BERSANI, 1995: 21).

Além dos textos médicos, os primeiros textos já falavam dessa marca social, ou metáfora, que tal doença deixava em alguns corpos profundamente marcados pela(s) epidemia(s), desde pânicos morais até ostracismo social. Susan Sontag, em 1988, deixa claro a marca social da AIDS em seu livro seminal "Aids and its metaphors". A autora diz que receber o diagnóstico positivo (em suas palavras, "to get AIDS" ou como diziase à época no Brasil, "pegar AIDS”) significava ser revelado, na maioria dos casos até o momento como membro de um certo grupo de risco, uma comunidade de párias (29). Assim como no texto de Sontag, Herbert Daniel procurou desde o início da epidemia discutir os efeitos da crise epidêmica além dos dados médicos, preocupado com esses efeitos sociais que o HIV/ AIDS deixava nas pessoas. Como disse Alfredo Sirkis,

Resistiu quatro anos durante os quais lutou, lutou, lutou, incessantemente, viajando pelo mundo, dando palestras, escrevendo artigos, negociando articulações internacionais. Herbert Daniel mudou a história da AIDS no Brasil. (SIRKIS, 1998, s.p.)

Mais recente, o livro de Lina Meruane também fala dessa marca no corpo homossexual ao discutir textos de autores como Pedro Lemebel, Severo Sarduy, Reinaldo Arenas e Mario Bellatin. Meruane discute a ideia de contágio discursivo:

Ese contagio del discurso se inició con la primera sospecha del misterioso mal. El sida y la muerte que cundía a su alrededor no solo detonarán la necesidad de relatos destinados a explicar la epidemia desde viejos parámetros del movimiento que remiten a las pestes pretéritas (MERUANE, 2012: 22)

João Silvério Trevisan (2004: 366) diz que Daniel foi um dos primeiros a "engajar-se nas campanhas nacionais contra a Aids". O primeiro texto de Herbert 
Daniel, de 1983 já fala da síndrome do preconceito (GUIMARÃES et all, 1989: 5). Nos anos 80, Herbert Daniel já rascunhava ideias que seriam fundamentais mais tarde no combate ao HIV/ AIDS e ao estigma que o vírus deixava em alguns corpos. Herbert Daniel responde de maneira precisa ao que Casper e Moore chamam de "moral panics" que veremos mais adiante.

\section{Os textos de Herbert Daniel}

Desde o seu retorno ao Brasil em 1981 até a sua morte em 1992, Daniel publicou vários textos. O mais conhecido, o seu relato sobre os anos da ditadura (nos moldes de vários outros volumes publicados à época) ainda é citado por muitos como referência aos anos da ditadura no Brasil. Todavia, Herbert Daniel também publicou para teatro, romances mais experimentais como "Meu corpo daria um romance" e "A fêmea sintética", passando por manifestos e textos teóricos e ensaios, alguns desses em conjunto com pesquisadores e outros autores como Richard Parker e Leila Míccolis.

Após o seu texto inicial em que relata os anos de resistência política e exílio, a literatura de Daniel assume um caráter experimental discutindo temas como a homossexualidade, a liberação sexual e a epidemia da AIDS. Assim, pode-se dizer que a obra de Herbert Daniel reflete os primeiros anos da epidemia. Fase em que Daniel tenta desmistificar a doença que já havia chegado antes mesmo do vírus no Brasil (contágio discursivo como vimos acima). Herbert Daniel diz em "A terceira epidemia" que "o primeiro impacto da AIDS no Brasil ocorreu sobretudo no imaginário social" (DANIEL, 1991).

Seus primeiros textos sobre o assunto deixam claro a confusão inicial que o tema gerou no público, nos jornais e na comunidade científica. O próprio termo - AIDS ainda não havia se solidificado na linguagem acadêmica. Uns usavam SIDA, termo que acabou sendo adotado em espanhol e francês, outros mantinham a sigla em inglês original. O texto de Daniel usa os dois termos procurando traçar uma genealogia da chegada do vírus HIV e do estigma da doença. Em “Alegres e Irresponsáveis abacaxis americanos: Imagens dos dias do medo (Dias, aliás que é anagrama de Aids)", o autor testa os limites do significado do termo médico traçando um paralelo com 'dias' já no início do livro. 
Para Daniel a ideia da doença chegou no Brasil antes mesmo dos primeiros casos reportados aqui. A SIDA, para Daniel, quando aparecem os primeiros casos, chega tardiamente em comparação à AIDS, "algo, o enigma AIDS, funciona como tal unanimidade: a SIDA deixa de ser meramente uma doença, uma questão de saúde pública, e passa a ser o "lugar do problema". (DANIEL, PARKER, 1990: 85). Daniel distingue, portanto, a ideia de aids da doença AIDS, como nos explica Cristiana Bastos em Global Responses to AIDS: Science in Emergency" afirmando que Daniel usa o termo "aids" em letras minúsculas para se referir ao fenômeno ideológico e político, um termo com muitos mais significados que a doença conhecida pelo acrônimo AIDS (68). Caio Fernando Abreu, escritor brasileiro, contemporâneo de Herbert Daniel também observa a chegada do pânico no Brasil antes da chegada do vírus mesmo, ou seja, dos primeiros casos noticiados pela imprensa. Na biografia de Abreu escrita por Paula Dip, há dois momentos significativos em que a opinião do autor corrobora a tese de Daniel. Primeiro em uma carta pessoal Caio F. Abreu diz:

É então, quando essa peste começa a sair das páginas dos jornais para atingir pessoas conhecidas, que você para e pensa: Meu Deus, a tal doença parece que existe mesmo. E dá medo. Porque te ameaça no que você tem de mais precioso: a sexualidade. Medo, medo, medo. (DIP, 2009: 209)

O segundo momento é um depoimento para a revista Isto é em que Abreu diz que "desde 1984, carrego a suspeita de estar contaminado. Meu psicanalista dizia: "Você não precisa fazer o teste, porque mentalmente já está infectado"” (DIP, 2009: 265). Herbert Daniel procura, na sua obra, mostrar não só os efeitos do vírus e da epidemia no corpo das pessoas, mas também os efeitos, muito mais fortes, na sua opinião, do vírus moral, da infecção social que chegara antes do vírus HIV.

O trabalho de Daniel como ativista reflete-se na sua obra literária e ensaística. Desde os primeiros passos da criação de um movimento social que lidasse com a crise epidêmica da AIDS no Brasil, Herbert Daniel figurou como peça central na tentativa de lidar com a questão. Como discute Amy Nunn:

In 1989, after a major AIDS conference in Montreal, many NGOs and AIDS activists, including Betinho, Herbert Daniel, Paulo Teixeira, and many others, began organizing to exchange information and develop broad 
strategies to influence public policy related to AIDS in Brazil. This resulted in Brazil's first NGO network and first joint articulation of several NGOs overarching human rights objectives, entitled the Declaration of Rights of Individuals Living with AIDS. The declaration outlined the movement's principles of nondiscrimination, social equity, democratic accountability, and participation of PLWHA in policy development (NUNN, 2009: 50).

O projeto humanista de Daniel fica claro em seus textos. Durante os anos 80 e 90, período em que exerceu seu ativismo político, Daniel procurava humanizar os doentes de AIDS evitando a vitimização, dando-lhes agência (termo que seria discutido mais tarde), ou seja, evitando o que Daniel chamava de morte civil, ou a perda do direito à vida mesmo vivos. De acordo com Daniel, o momento de detecção do vírus correspondia ao momento da morte civil das pessoas infectadas e era preciso lutar contra essa morte forçada. Também, ele procura tirar a AIDS do gueto, mostrando que como questão de saúde afeta a todos, não somente ao grupo inicialmente destacado como vítimas - os homossexuais masculinos. Para o autor, "a AIDS veio aumentar a lista de análises etnocêntricas e racistas" (DANIEL; PARKER, 1991: 36).

Daniel, em sua obra ensaística e literária antecipa as ideias relacionadas ao estigma e ao preconceito que a aids trouxe para o Brasil ainda antes da chegada do HIV e da detecção dos primeiros casos em São Paulo. Como diz o editorial do boletim da ABIA de junho de 2015:

O retorno do vírus ideológico marca de forma definitiva o retrocesso que, nos últimos anos, impulsionado pelo conservadorismo, tem impactado negativamente a sociedade brasileira na resposta à AIDS no país. Afinal, como nos antecipou o brilhante Herbert Daniel, o vírus ideológico é muito mais difícil de ser confrontado do que o vírus biológico. (ABIA 2015: 1)

Tantos os romances de Daniel quanto os textos ensaísticos mostram bem a paranoia que se formou quando o assunto era AIDS. Gilbert Herdt discute a noção de pânico moral (moral panics, no original) em seu livro "Moral Panics, Sex Panics - Fear and the Fight over Sexual Rights”. Para o autor pânicos morais são característicos em, states that experience times of divided public opinion, changing social, economic and political circumstances, and a clash between state mechanisms of control and the free expression and individual elaboration of sexuality" (HERDT, 2009: 32). 
A AIDS era um caso de crise de saúde pública: "everyone discussed. It was a frightening epidemic that (...) generated changes in activism, public health practices, clinical research, funding streams and sexual politics" (CASPER; MOORE, 2009: 85). A epidemia colocou em evidência a homossexualidade, e com isso os pânicos relacionados a tais práticas sociais. A imediata associação da doença com o exótico, o elegante e os ricos que havia acometido os Estados Unidos é traduzida para os noticiários brasileiros. Bastos nos lembra do primeiro caso brasileiro noticiado na mídia, do costureiro Markito:

The first publicized case of AIDS in Brazil reinforced its stereotype as a disease of the rich and famous. The disease struck São Paulo's well-known gay designer Markito in 1983. Markito was seen as a cosmopolitan gay traveler who was believed to have contracted AIDS in New York. He was also portrayed as the irresponsible type who went back to the metropolis for fun and partying instead of getting treatment (BASTOS, 1999: 72).

Caio Fernando Abreu, outro autor que também morreu em decorrência do HIV escreveu sobre a epidemia não só na sua obra ficcional, mas também em seus textos pessoais e com cunho ensaístico. Fernando Arenas diz que suas histórias são produtos de "an era besieged by panic over the body, fear of sex and AIDS" (ARENAS, 2002: 16). Assim como Abreu, os romances de Herbert Daniel também respondem aos anseios de uma época em que há medo do corpo, medo do sexo, como disse Caio Fernando Abreu,

São Paulo atualmente é uma cidade tomada pela paranóia da AIDS. Pelo menos na faixa de gente como a gente (...) Conheço pessoas que não se tocam mais. O que é que se faz quando aquilo que era possibilidade de prazer - o toque, o beijo, o mergulho no corpo alheio capaz de nos aliviar da sensação de finitude e incomunicabilidade - começa a se tornar possibilidade de horror? Quando amor vira risco de contaminação? (BESSA, 1996: 82)

Caio Fernando Abreu nos remete à comunidade de párias que Susan Sontag observa em seu livro de 1988. Herbert Daniel entende essa comunidade de párias e tenta dar visibilidade a um grupo que ganha espaço social, primeiramente como produtos da 
medicina, doentes pela homossexualidade, e agora doentes, mais uma vez, pela aids. De acordo com Sontag, temos dois tipos de pessoas, os culpados que estão sendo punidos por suas perversões e os inocentes, afetados por tais comportamentos. A comunidade descrita no romance "Alegres e irresponsáveis..." entra em choque no momento em que os "cidadãos de bem" sentem-se ameaçados pelos comportamentos de risco dos homossexuais da vila. Herbert Daniel em sua obra ficcional e ensaística mostra que não há culpados ou inocentes e sim, cidadãos que precisam de atenção do estado independentemente de sua condição social, racial ou status médico. Como ele diz em uma reportagem produzida pela TV Manchete em 1989:

Eu sou escritor homossexual e estou doente de AIDS. Isso me torna um cidadão absolutamente comum, um brasileiro como quase todos os outros. Oprimido, mas cheio de esperança. (DANIEL, 1989b: s.p.)

\section{A obra ficcional de Herbert Daniel}

Em termos de problematização e levantamento de temas importantes, a ficção de Daniel é tão eficiente quanto os ensaios. Os projetos literários de Daniel não metaforizam a aids, ele menciona o vírus e a doença em decorrência do HIV sem floreios. Mais do que uma metáfora, a AIDS é parte do cotidiano das pessoas e serve como ponto de discussão para os problemas que ele observa em um país recém-saído de uma ditadura tentando se reestruturar economicamente e socialmente. Como diz Bessa:

A habilidade de Daniel ao tratar a AIDS é mais bem-sucedida em depoimentos e ensaios (ver 1983,1989e 1991), onde ele consegue discorrer sobre inúmeros assuntos (como, por exemplo, a inoperância governamental frente à AIDS, a estigmatização dos chamados "grupos de risco", a clandestinização do doente de AIDS) com uma lógica e uma clareza incomuns (BESSA, 1997: 69).

Alegres e Irresponsáveis Abacaxis Americanos. Imagens dos dias do medo (Dias, aliás, é anagrama de Aids) publicado em 1987 apresenta como parte do enredo personagens que sofrem discriminação por serem portadores do vírus HIV ou por serem possíveis portadores do vírus. O romance conta a história de vários personagens que 
vivem em uma mesma vila em uma grande cidade. Nos moldes d'O Cortiço de Aluísio de Azevedo, "Alegres e Irresponsáveis Abacaxis..." reúne em um mesmo espaço urbano, personagens típicos, ou "tipos" literários que apresentam suas narrativas em paralelo a questões sociais.

A vila é ameaçada pelos sonhos empreendedores de um dos filhos da dona de todas as casas. Em suas casas, vivem, entre outros personagens, Ia, uma viúva de um desaparecido político. Dona Rita, uma outra viúva, mais velha, que toma conta da vida de todos e instala o pânico moral. Dona Carlota, a dona de todas casas, com seus filhos e netos. O filho mais velho, um poeta, que se exibe para os outros e acredita numa vida mais pacata. O outro filho, empreendedor, que pretende vender as casas para uma grande imobiliária. Ao redor da vila ainda vivem um médico e um padre que procuram trazer a voz da ciência e da moral para os moradores acometidos pelo medo da contaminação.

Herbert Daniel inicia o romance narrando sobre o estigma no corpo homossexual. As cenas inicias se dão durante o velório de Gau, 'acusado' de ser gay e como tal de haver "morrido de AIDS" (DANIEL,1987: 28). Roi, o carteiro da vila em que a ação do romance se desenvolve tenta explicar aos vizinhos que a "peste" não “pega” no ar, mas o pânico, sim. Rita, a senhora mais velha diz durante o velório:

"Hortencília, cuidado, é preciso tomar muito cuidado! Não se sabe do que ele morreu. Pode ser da tal de Aids. Você sabe que ele desmunhecava. Essa gente, todo mundo sabe, está espalhando isso. (DANIEL, 1987: 21)

Daniel não poupa nenhum cidadão do pânico moral e do medo da contaminação. Ainda no velório Adílio implora a Deli, seu amigo para ir embora do velório já que "Aids mata bicha num piscar de olho" (DANIEL, 1987: 22). Como discutimos anteriormente, ainda que as pessoas não estejam sujeitas ao vírus, o discurso já está contaminado.

Na terceira sequência do romance, Daniel exemplifica a ideia de pânico moral de Herdt com uma cena em que os vizinhos queimam a casa do morto para evitar a contaminação. O pânico moral toma conta da população local e vê o incêndio e destruição de todos os pertences do recém-morto como única solução para que todos se salvem. Ainda sobre o pânico e a contaminação do discurso. Dona Rita em determinado momento espalha a ideia de que as lágrimas dos homossexuais podem contagiar as 
pessoas: "Esta foi uma notícia que recortei especialmente para a senhora. Está aí com todas as letras: é um perigo, as lágrimas dos homossexuais. Estão cheias de Aids" (DANIEL, 1987: 87). O contraponto discursivo surge através das vozes de Roi, o carteiro e do padre local. O primeiro procura acalmar a população tentando manter a razão frente aos discursos de pânico propagados. Por exemplo, Roi diz para os vizinhos que "por causa das invasões epidêmicas e do pânico. Isto é capaz até de exterminar com a solidariedade aos mortos e feridos...” (DANIEL, 1987: 85). Já Padre Félix diz que,

Há um pânico irracional se disseminando aos poucos, por causa do sensacionalismo, da irresponsabilidade da divulgação dos dados... Cria um campo de cultivo para maiores calamidades - quase suplica Felix - O mais importante é esclarecer todos sobre a realidade da Aids... (DANIEL,1987: 107)

Daniel coloca na voz de seus personagens, a voz do preconceito - através do pânico moral - e a voz da razão, através da ciência (mesmo criticando em seus ensaios a maneira como a medicina e a ciência elaboram o seu discurso a respeito da AIDS). Ambos discursos pretendem mostrar maneiras de lidar com a epidemia e com o preconceito. Como dissemos antes, a epidemia maior, no projeto político-literário de Daniel é, na verdade, a desinformação, essa sim contagiosa e perigosa. Herbert Daniel não minimiza a epidemia e seus efeitos, pelo contrário, ele afirma constantemente que não tem "a mínima intenção de diminuir a gravidade da doença” (DANIEL, 1991: 11), porém ela deixa claro a terceira epidemia, o contágio do preconceito.

Dois trechos próximos, parte de um longo diálogo entre as lideranças da vila exemplificam esses dois tipos de vozes ao longo do romance. Primeiramente o médico procura explicar aos seus amigos a questão dos grupos de risco (ainda em discussão à época do romance) dizendo que "os homossexuais são um grupo de risco e não um agente da epidemia. Eles se arriscam a pegar a doença, não necessariamente a espalhar a epidemia pela vizinhança" (DANIEL, 1987: 123). Mais adiante Hermírio diz que não é preconceituoso e segue explicando: "até tenho amigos homossexuais. Mas não sei como nos misturar com os ... despaginados" (DANIEL, 1987: 126). Portanto, a sua obra literária, ainda que ficcional, procura, através da voz de seus personagens explicar questões importantes para o leitor. 
Daniel mantém até o final do romance a ideia do pânico ser o inimigo público número um. Nas últimas páginas, momento em que a polícia precisa retirar os moradores da vila para que as construções comecem, um policial ameaça matar Adílio ao saber que ele tem o vírus:

Aids?! - espanta-se o policial. Apontando a metralhadora para a Adílio, comando: - Não se mova daí, senão atiro. Atenção, todos! É um caso de peste. Atirem para matar, se ameaçar se aproximar. Chamem a Higiene Pública. Urgente. Chamem também a Companhia Municipal de Lixo, para o transporte. (DANIEL, 1987: 309)

O texto de Daniel pretende trazer luz aos problemas que surgem durante uma possível epidemia. O autor traz à luz a comunidade de párias que Sontag menciona e mostra que a epidemia funciona não só como uma metáfora de controle sob os corpos dentro um modelo Foucaultiano, mas também dentro de um sistema capitalista que coloca o lucro pessoal acima da comunidade (através da expulsão dos moradores para a construção de um grande empreendimento imobiliário). Através de seu trabalho de construção literária, ele procura informar complementando o seu trabalho ensaístico. Seus textos se complementam como um diário acadêmico e pessoal destacando a importância de se entender a epidemia como agente em primeira pessoa, tanto como um ativista político como um indivíduo preocupado com o seu meio.

\section{A obra ensaística}

Herbert Daniel escreveu três livros de ensaios discutindo a homossexualidade e a epidemia da AIDS no Brasil nos anos 80. O primeiro, em 1983, em parceria com Leila Míccolis, "Jacarés e Lobisomens: dois ensaios sobre a homossexualidade”. O segundo, "Viver a vida", obra bilíngue em português e inglês pensando na divulgação e troca de ideias com ativistas de outras partes do mundo. E por fim, escreveu com Richard Parker, "Aids a terceira epidemia: Dois olhares se cruzam numa noite suja", publicado em 1991. Além dos volumes citados acima, Daniel escreveu para o Boletim da ABIA e para jornais e revistas da época.

Assim como já demonstramos na obra ficcional, nos textos ensaísticos de Herbert Daniel mais do que o vírus, há a doença moral que se instalara na sociedade 
antes até que o próprio vírus. Herbert Daniel diz que a sociedade está doente de aids, mas não da síndrome da imunodeficiência adquirida, e sim do preconceito e do pânico moral. Voltamos a ressaltar que ele não pretendia diminuir a gravidade da epidemia, mas entender a gravidade do pânico moral:

Pode-se dizer, sem nenhum recurso a nenhuma metáfora, que a nossa sociedade está doente de Aids. Doente de pânico, de desinformação, de preconceitos, de imobilismo diante da doença real. Medidas eficazes contra a epidemia de HIV passam por medidas concretos no combate ao vírus ideológico. Isto significa: informação correta, ações eficientes, desmistificação do medo, esvaziamento dos preconceitos, exercício permanente da solidariedade. (DANIEL, 1989: 21)

Durante o início da década de 80, a imprensa brasileira noticiava a doença de maneira sensacionalista usando termos como "enigma" (Revista Veja de 15 de junho de 1983: "O enigma que mata"), associação direta com a homossexualidade (Revista Veja de 17 de julho de 1982) e também a ideia de ser uma doença que vinha dos países desenvolvidos. Existia quase um desejo local de que fossem detectados casos dessa misteriosa doença como forma de alinhamento a essas superpotências ocidentais. A associação do vírus com partes mais pobres da sociedade se daria mais tarde, já no final da década de 80 e começo dos anos 90 quando a epidemia se espalha pela África e por grupos sociais menos favorecidos (ou grupos menos favorecidos passam a ganhar visibilidade). Como observamos anteriormente, a primeira personalidade brasileira a ser noticiada como vítima da AIDS, Markito, um conhecido 'jet-setter' acabou reforçando os preconceitos que vinham da imprensa internacional. Como diz Daniel, "a primeira vítima registrada de AIDS, no Brasil, foi um famoso costureiro. Certamente adquiriu o vírus em terras americanas” (DANIEL, 1983: 123).

Herbert Daniel analisa o momento em questão observando que, "antes mesmo que qualquer médico registrasse um único caso verificável de AIDS, a imprensa, sobretudo a sensacionalista, marcava a chegada da "peste gay", no Brasil, com uma inevitabilidade" (DANIEL, 1991: 33). Já em “Jacarés e Lobisomens" escrito com Leila Míccolos em 1983, Daniel faz um levantamento de notícias dos mais variados veículos de informação mostrando como as notícias passam "sutilmente do relatório médico ao 
pregão profético, embarcando pelas viagens de ficção científica", sem "esquecer da galhofa" (DANIEL, 1983: 124) .

Já em 1983, Herbert Daniel alerta para os perigos dos preconceitos relacionados ao vírus. O discurso vigente da época reproduz o que se dizia sobre a sífilis e outras doenças venéreas ainda no século XIX. Como diz Marques (2003: 28), “A luta contra a sífilis no Brasil, naquele período, e os conceitos de moral, sexualidade, marginalização e outros foram utilizados como pontos de comparação para a discussão sobre a Aids e a possível repetição daquela história”. Daniel mantém-se atento a tal prática discursiva e procura discutir maneiras de diminuir o preconceito em relação a práticas sociais e/ou sexuais mostrando que as opções individuais e orientações sexuais não poderiam ser vítimas de escrutínio médico e social.

A crítica em relação a chegada da aids antes da AIDS no Brasil leva Daniel a pensar na relação entre o Brasil e os países mais ricos, especialmente Estados Unidos e França e a forma como no Brasil se adotou, de início, um modelo exportado sem levar em consideração as caraterísticas únicas da realidade brasileira. Daniel aponta que no Brasil, "anunciou-se uma epidemia que "parecia" com a norte-americana, esperou-se uma epidemia que seguisse o padrão ocidental, investigou-se, nos consultórios e nas tabelas da epidemiologia local, o modelo preconcebido" (DANIEL, 1991: 34). Tal modelo importado acaba em, de acordo o autor, em desastrosas consequências já que ao se adotar um modelo que não condiz com a realidade brasileira, rejeita estruturas identitárias e práticas sociais comuns no Brasil.

Richard Parker, coautor com Daniel em seu último ensaio sobre a AIDS/ HIV levanta essa problemática em "A Construção da Solidariedade: AIDS, Sexualidade e Política no Brasil" publicado em 1994, mostrando que é preciso compreender as práticas sexuais e sociais no Brasil para que se possa discutir formas de prevenção mais eficientes tendo em vista que nem todo modelo internacional funcionaria no Brasil. Daniel e Parker na introdução de "A terceira epidemia" nos alertam que é "preciso analisar as determinações culturais da epidemia de AIDS, para não só melhor entender sua evolução, como para fundamentar políticas preventivas mais eficientes”, pois, de acordo com os autores, a "AIDS, certamente, tem a cara da cultura da sociedade que se desenvolve" (DANIEL, PARKER, 1991: 10).

Toda epidemia tem, em si, uma característica viajante ("viajera" como descreve Lina Meruane em "Viajes Virales"). A epidemia da AIDS não fugiria de tal predicado. Enfermidades têm viajado e cruzado fronteiras por séculos, o que seria diferente nessa 
epidemia contemporânea? Daniel nos alerta para a sua associação com a homossexualidade. Desde os primeiros casos, a AIDS e o HIV - quando isolado foram associados à praticas sexuais “dissidentes". De início, uma doença de homossexuais ricos, depois uma doença de homossexuais em geral e viciados em drogas. A ainda frágil identidade homossexual em formação no Brasil passa a ser associada ao uso de drogas e à morte por uma doença que ataca àqueles que se recusam a manter uma vida dentro do padrão. Como afirma Leo Bersani, nada fez o homem gay mais visível do que a AIDS (1995: 19). A uniformização de todas as identidades de gênero e orientações sexuais que não respondiam ao anseio cis-gênero e heterossexual colocou uma parcela grande da população visível através do pânico de uma doença que afligia a todos que estavam foram dos valores morais:

O esquematismo faz uma salada onde se lê: Homossexualidade $=$ promiscuidade e "vida libertina" = uniformização de um grupo socialmente homogêneo = doença.

A confusão que faz da homossexualidade uma "doença" é uma forma de preconceito tradicional. (DANIEL, 1983: 129).

Aos finais do século XIX a homossexualidade passa a ser medicalizada e analisada e passa-se a falar do surgimento do homossexual como categoria, ou seja, a homossexualidade converte-se em uma doença. A partir dos anos $50 \mathrm{com}$ os primeiros grupos de liberação gay na Europa e mais tarde nos Estados Unidos, passa-se a dissociar a ideia de homossexualidade como doença. Surgem em várias partes do mundo movimentos de liberação homossexual como o grupo Somos na Argentina e o ativismo através da revista Lampião da Esquina no Brasil. Com a epidemia da AIDS, a homossexualidade passa a ser diretamente associada à doença. Ela carrega uma doença e tal doença mata. Tais preconceitos ficam visíveis no discurso médico-legal da época e também na impressa. Daniel pretende mostrar através de seus livros como tal discurso é muito mais nocivo que a própria doença em si.

\section{Conclusão}


Herbert Daniel falava em morte cívica dos "doentes" de aids, uma morte anunciada. Daniel argumentava que morrer, todos iriam incluindo o próprio autor no grupo. Estar vivo, para ele, já era um ato de desobediência civil, portanto mantê-lo vivo, em textos e em ideias é tentar manter tais atos de desobediência civil, ainda tão importantes hoje em dia. O trabalho de Herbert Daniel, mencionado em todos os livros que lidam com a história da epidemia no Brasil, é de extrema importância para quem pretende estudar a história da AIDS dentro de uma perspectiva brasileira. Entender seus textos, traz à luz questões que foram - e ainda são - fundamentais para compreendermos de que maneira uma epidemia com as dimensões que a AIDS/ HIV possui pode afetar a sociedade de maneira geral. Ainda que, trinta anos depois muita coisa tenha mudado, especialmente no quesito linguagem, não se fala em "ter aids", "pegar aids", "morrer de aids" e "aidético" (uma ingrata invenção da linguagem médica dos anos 80) ter se tornado politicamente incorreta, o discurso ao redor da infecção e agentes afetados pelo vírus ainda traz uma carga grande de preconceito. Portanto, falar dele e de sua obra é importante porque apesar dos avanços ainda há estigma e marcas no corpo da população guei (como ele escrevia gay).

A desobediência civil de Daniel é muito importante para todos nós ainda hoje. Herbert Daniel não teve tempo de ver uma nova geração achando que se pode viver com o vírus, não viu as festas barebacking se proliferando, bug chasers.... Herbert Daniel não pôde em vida, durante a sua desobediência civil, ver os avanços políticos da distribuição universal de remédios no Brasil, das vitórias para os "doentes" na OMS, ou até dos profiláticos hoje em dia, porém o seu trabalho resiste de maneira atual e precisa quando falamos de uma possível história da AIDS no Brasil e de que maneiras os primeiros ativistas nos anos 80 trilharam o caminho para as futuras gerações que trabalham no campo ou experienciam questões relacionadas ao HIV/ AIDS nos dias de hoje e no futuro.

\section{Bibliografia}

ABIA (1989a). Boletim da ABIA, volume 5. In: http://abiaids.org.br/categoria/acervoabia/boletins/boletim-abia-pt-br. Acessado em 09 de março de 2016.

ABIA (1989b). Boletim da ABIA, volume 8. In: http://abiaids.org.br/categoria/acervoabia/boletins/boletim-abia-pt-br. Acessado em 09 de março de 2016.

ABIA (2015). Boletim da ABIA, volume 60. In: http://abiaids.org.br/categoria/acervoabia/boletins/boletim-abia-pt-br. Acessado em 09 de março de 2016. 
AMARAL, Ricardo Batista (2011). A vida quer é coragem. A trajetória de Dilma Roussef, a primeira presidenta do Brasil. Rio de Janeiro: Sextante.

ARENAS, Fernando (2002). Small Epiphanies in the Night of the World. The Writings of Caio Fernando Abreu. In: QUINLAN, Susan Canty and ARENAS, Fernando (orgs). Lusosex - Gender and Sexuality in the Portuguese-speaking world. Minneapolis: University of Minnesota Press, pp. 12-33.

BASTOS, Cristiana (1999). Global Responses to AIDS. Science in Emergency. Bloomington: Indiana University Press.

BESSA, Marcelo (1997). Histórias Positivas. Rio de Janeiro e São Paulo: Editora Record.

BERSANI, Leo (1995). Homos. Cambridge: Harvard University Press. (2010). Is the Rectum a Grave? And Other Essays. Chicago: Chicago University Press.

BOLACHA, Rafael (2012). Uma vida positiva. São Paulo: Editora Cidade Viva.

CASPER, Monica J.; MOORE Lisa Jean (2009). Missing Bodies. The Politics of Visibility. New York: New York University Press.

DANIEL, Herbert (1980). Companheiros. Lampião da Esquina, 22, p. 10. (1982). Passagem para o próximo sonho. Rio de Janeiro: Codecri. (1987). Alegres e irresponsáveis abacaxis americanos. Rio de Janeiro: Espaço e Tempo.

(1989a). Vida antes da morte. Life Before Death. São Paulo: Tipografia Jaboti.

(1989b). Viva a Vida: O amor e a AIDS nos anos 80. TV Manchete, 1988.

Disponível em: https://www.youtube.com/watch?v=-0-mk-HW2_c Acesso em 07 mar 2016.

; PARKER, Richard (1990). Aids a terceira epidemia. Dois olhares se cruzam numa noite suja. São Paulo: Iglu.

; Míccolis, Leila (1983). Jacarés e Lobisomens. Dois ensaios sobre a homossexualidade. São Paulo: Edições Achiamé.

DIP, Paula (2009). Para sempre, eu. Caio F. Cartas, conversas, memórias de Caio Fernando Abreu. Rio de Janeiro: Editora Record.

FOSTER, David William (org) (1994). Latin-American Writers on Gay and Lesbian Themes: A Bio-Critical Sourcebook. Westport: Greenwood Press.

FUNDAÇÃO VERDE HERBERT DANIEL (1989). In: http://www.fvhd.org.br/page/herbert-daniel. Acessado em 09 de março de 2016.

GABEIRA, Fernando (1979). O que é isso, companheiro? Rio de Janeiro: Codecri.

GALVÃO, Jane (2000). AIDS no Brasil. A agenda de construção de uma epidemia. São Paulo: Editora 34.

GUIMARÃES, Carmen Dora, DANIEL, Herbert, GALVÃO, Jane (1988). A questão do preconceito. Boletim ABIA, 3, pp. 2-3.

HALPERIN, David. (2012). How to be Gay. Cambridge: The Belknap Press of Harvard University Press.

HERDT, Gilbert (2009). Moral Panics, Sex Panics - Fear and the Fight over Sexual Rights. New York: New York University Press.

LIKOSKI, Stephan (1992). Coming Out. An Anthology of International Gay and Lesbian Writings. New York: Pantheon Books.

MARQUES, Maria Cristina da Costa (2003). A história de uma epidemia moderna. A emergência política da AIDS/ HIV no Brasil. São Carlos: Rima Editora.

MERUANE, Lina (2012). Viajes Virales. Chile: FCE.

NUNN, Amy (2009). The Politics and History of AIDS Treatment in Brazil. New York: Springer. 
PARKER, Richard (1994). A construção da solidariedade: AIDS, sexualidade e política no Brasil. Rio de Janeiro: Abia, IMS-UERJ, Relume-Dumará

POLIZZI, Valéria (1997). Depois daquela viagem. Diário de bordo de uma jovem que aprendeu a conviver com a AIDS. São Pualo: Editora Ática.

SIRKIS, Alfredo (1998). Os carbonários, memórias da guerrilha perdida. São Paulo: Global Editora.

SONTAG, Susan (1988). Aids and its Metaphors. New York: Farrar, Straus and Giroux.

TREVISAN, João Silvério (2004). Devassos no paraíso: A homossexualidade no Brasil da colônia à atualidade. São Paulo: Editora Record.

Artigo recebido em 20 de fevereiro de 2016.

Aprovado em 25 de março de 2016.

DOI: 10.12957/intellectus.2016.23841 